\title{
Studies on the frequency and pathogenesis of liver involvement in rheumatoid arthritis
}

\author{
L. FERNANDES, S. SULLIVAN, I. G. MCFARLANE, B. M. WOJCICKA, \\ T. W. WARNES, A. L. W. F. EDDLESTON, E. B. D. HAMILTON, AND \\ ROGER WILLIAMS
}

From the Liver Unit and the Rheumatology Department, King's College Hospital, London, and the Department of Gastroenterology, Manchester Royal Infirmary, Manchester

SUMMARY A systematic prospective survey of 100 outpatients with rheumatoid arthritis revealed that 45 had biochemical evidence of liver disease. In most cases this was due to increases in total serum alkaline phosphatase (ALP) and/or gammaglutamyl transpeptidase (GGT). Examination of serum ALP isoenzyme profiles in 50 of the patients showed that the liver isoenzyme was the sole or major component in 44 patients, including many with normal total ALP levels. $18 \%$ had raised serum liver ALP together with raised GGT, suggestive of an underlying hepatobiliary lesion. No correlation could be detected between raised serum levels of liver enzymes and the age or sex of the patient, duration or severity of arthritis, and drug or alcohol history. However, there was a significant correlation between raised serum ALP and lacrimal or salivary gland dysfunction. It is suggested that immunological mechanisms may be involved in the development of hepatic abnormalities in rheumatoid arthritis.

The association of rheumatic disorders with liver disease is well known but poorly understood. Overt clinical evidence of liver disease in uncomplicated rheumatoid arthritis is considered to be uncommon, although hepatomegaly has been reported in up to $20 \%$ of patients (Webb et al., 1975; Tiger et al., 1976). Abnormalities in the biochemical tests of liver function are more frequent, with elevated serum alkaline phosphatase levels being found in up to $50 \%$ of rheumatoid arthritis patients (Lefkovits and Farrow, 1955; Cockel et al., 1971; Webb et al., 1975). Concomitant increases in gammaglutamyl, transpeptidase and leucine amino-peptidase levels suggest that the alkaline phosphatase may have been of hepatic rather than bone origin. Histological abnormalities on liver biopsy have been found in $25 \%$ to $50 \%$ of rheumatoid patients (Lefkovits and Farrow, 1955; Webb et al., 1975; Dietrichson et al., 1976), the most frequent change, apart from fatty liver, being a mononuclear cell infiltration of the portal tracts suggestive of a biliary rather than an hepatocellular lesion.

The mechanisms underlying the development of

Accepted for publication 19 December 1978.

Correspondence to Dr Roger Williams, Liver Unit, King's College Hospital Medical School, Denmark Hill, London SE5 8RX. these liver abnormalities are unknown, though the hepatotoxic properties of some of the drugs used in treatment may be a factor. However, the sicca syndrome (manifest as xerostomia and xerophthalmia) is a common systemic manifestation both of rheumatoid arthritis (Bioch et al., 1965) and of the 'autoimmune' liver diseases, chronic active hepatitis and primary biliary cirrhosis (Golding et al., 1970). Since immune responses to salivary antigens have been implicated in the development of the sicca syndrome in both joint and liver diseases (Soberg and Bertram, 1968; Anderson et al., 1973; McFarlane, et al., 1976) it seems likely that the occurrence of liver lesions in rheumatoid arthritis may have an immunological basis.

In the present paper we report the results of a prospective survey of 100 patients with rheumatoid arthritis, in which we attempted, firstly, to determine the incidence and nature of the biochemical abnormalities suggestive of liver disease, and, secondly, to establish whether such abnormalities are specifically associated with lacrimal or salivary gland dysfunction.

\section{Patients and methods}

One hundred consecutive outpatients (67 females, 33 males) with classical or definite rheumatoid arthritis 
(Ropes et al., 1958) were evaluated. Ninety-two were being treated with non-steroidal anti-inflammatory drugs, 30 with corticosteroids, 31 with D-penicillamine, and 11 were receiving chrysotherapy. A detailed history of alcohol consumption was obtained together with any past history of hepatic or biliary tract disease, and patients were systematically examined for cutaneous stigmata of liver disease and clinical enlargement of the liver and spleen. Severity of arthritis was assessed by the articular index, grip strength, and duration of morning stiffness, and the presence of nodules or vasculities was noted.

Lacrimal gland function was assessed by Schirmer's test and xerophthalmia diagnosed if patients showed $5 \mathrm{~mm}$ or less moistening of the filter paper strips in both eyes in 5 minutes. This limit was chosen because it had been found to show a good correlation with results of rose-Bengal staining (Sullivan et al., 1978). Total saliva flow was measured by spitting into a beaker all saliva produced during 10 minutes while chewing mint-flavoured gum. Xerostomia was diagnosed in patients who produced less than $12 \mathrm{ml}$, which was 2 standard deviations below the mean obtained in 20 normal subjects under identical conditions (Sullivan et al., 1978).

Laboratory investigations included a blood count and erythrocyte sedimentation rate. Rheumatoid factor was estimated by latex agglutination. Antinuclear, antismooth muscle, and antimitochondrial antibodies were detected by immunofluorescence and hepatitis $B$ virus surface antigen and antibody by radioimmunoassay (AUSRIA II, Abbot Laboratories). In addition to serum albumin and globulin concentration, biochemical evaluation of liver function included total bilirubin, aspartate aminotransferase, total alkaline phosphatase, and gammaglutamyl transpeptidase. In 50 unselected patients alkaline phosphatase isoenzymes were determined by polyacrylamide gel electrophoresis (Warnes et al., 1976) by one of us (T.W.), who was unaware of the clinical and biochemical findings at the time.

\section{Results}

In the 100 patients (mean age $58 \pm 10$ years) the mean duration of arthritis was $11 \pm 10$ years. The mean grip strength and articular index were $103 \pm$ $68 \mathrm{mmHg}$ and $9 \pm 5$ respectively, and the mean duration of morning stiffness was $42 \pm \mathbf{4 0}$ minutes. There were no significant differences between males and females in these parameters. None of the patients had hepatomegaly, splenomegaly, or any cutaneous stigmata of liver disease. In no patient was $\mathrm{Hb} \cdot \mathrm{Ag}$ detectable but $15 \%$ had $\mathrm{Hb}_{\mathrm{s}} \mathrm{Ab}$-an incidence similar to that reported for a control population (Reed et al., 1974).

LIVER FUNCTION TESTS

Total bilirubin was normal in all patients. Serum albumin was low in 5 , ranging from 29 to $34 \mathrm{~g} / 1$ 在 (lower normal limit, $35 \mathrm{~g} / \mathrm{l}$ ), while 2 others had marginal elevations of aspartate aminotransferase of 54 and $59 \mathrm{IU} / 1$ (upper normal limit, $50 \mathrm{IU} / \mathrm{l}$ ). ฏ Thirty-five patients had a total serum alkaline $\vec{\circ}$ phosphatase (ALP) in excess of $100 \mathrm{IU} / 1$, and 19. had a raised gammaglutamyl transpeptidase (GGT). $\vec{\omega}$ There were no statistical associations between elevations in serum ALP and the patients' sex, $\frac{0}{2}$ duration, or severity of arthritis, drug or alcohol $\omega$ history. Patients with raised serum ALP had a o higher median age (63.5 years) than those with 0 normal ALP levels (59 years), but this difference was not statistically significant. Raised total serum ALP was found in 2 of 3 patients with a past history of jaundice and in 2 of 3 others who had had cholecystectomies.

SALIVARY AND LACRIMAL GLAND FUNCTION

Fifty-eight patients had objective evidence of in paired lacrimal or salivary secretion, 26 with xerop thalmia, 18 with xerostomia, and 15 with bot?. There were no apparent clinical differences between those with and without impaired secretion. However, 27 of the 58 had elevated serum levels of ALP-a significantly $(\mathrm{P}<0.01)$ higher incidence than that $\stackrel{\mathbb{Q}}{\circ}$ ( 8 out of 42 ) observed in patients with apparently $\overrightarrow{\vec{O}}$ normal salivary and lacrimal gland function. 3 Furthermore, as a group, patients with xerostomia and/or xerophthalmia had significantly higher ALPO levels than those without either of these features (Table 1). A similar trend was noted for GGT, 0 raised levels of this enzyme being found in 15 of the

Table 1 Serum levels of total alkaline phosphatase and gammaglutamyl transpeptidase in patients with rheumatoid arthritis (means $\pm S D$ )

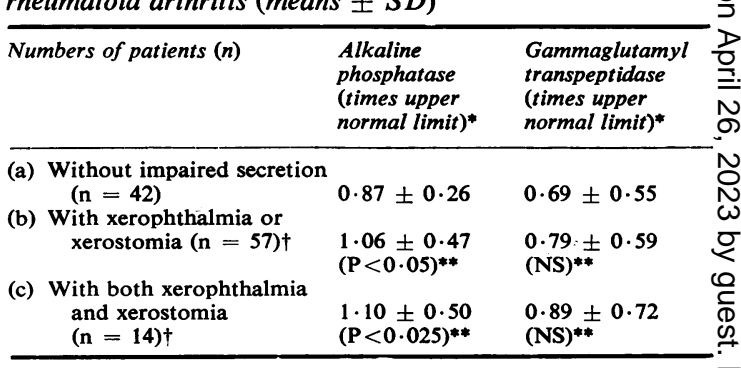

*Upper normal limits: alkaline phosphatase: $100 \mathrm{IU} / 1$; gammaglutamyl transpeptidase: 45 (males) and 35 (females) IU/1. †OneO patient receiving barbiturates excluded. ** Statistical comparisons $\overrightarrow{\mathbb{Q}}$ versus (a) $\mathrm{NS}=$ not significant. 
58 with, and in only 4 of the 42 without, xerostomia or xerophthalmia, but this difference did not achieve statistical significance $\left(\chi^{2}=3 \cdot 23 ; 0 \cdot 1>P>0.05\right)$.

\section{AUTOANTIBodies}

Antimitochondrial antibody was found in low titre $(1: 10)$ in only 1 patient, a 54-year-old woman with rheumatoid arthritis of 12 years' duration complicated by impaired lacrimal gland secretion. She was seropositive $(1: 1024)$ and had an elevated serum ALP of liver origin, as determined by electrophoresis, together with a raised GGT. Smooth muscle antibodies were found in 7 patients at a titre of $1: 10$ in 6 and 1:20 in 1. Antinuclear antibodies were present in 19 patients in titres ranging from $1: 10$ to $1: 160$. The clinical and biochemical features of the patients with smooth muscle and antinuclear antibodies were not different from those who were antibody negative. Rheumatoid factor was detected in 67 patients at titres ranging from $1: 32$ to $1: 1024$.

\section{ALKALINE PHOSPHATASE ISOENZYMES IN 50 PATIENTS}

Fifteen of the 50 patients whose sera were examined for ALP isoenzymes had an elevated total ALP (Table 2). Nine of these had the liver isoenzyme as the sole component of the main electrophoretic band position, while the remaining 6 had both liver

Table 2 Results of biochemical, tear, and salivary flow studies in 50 patients

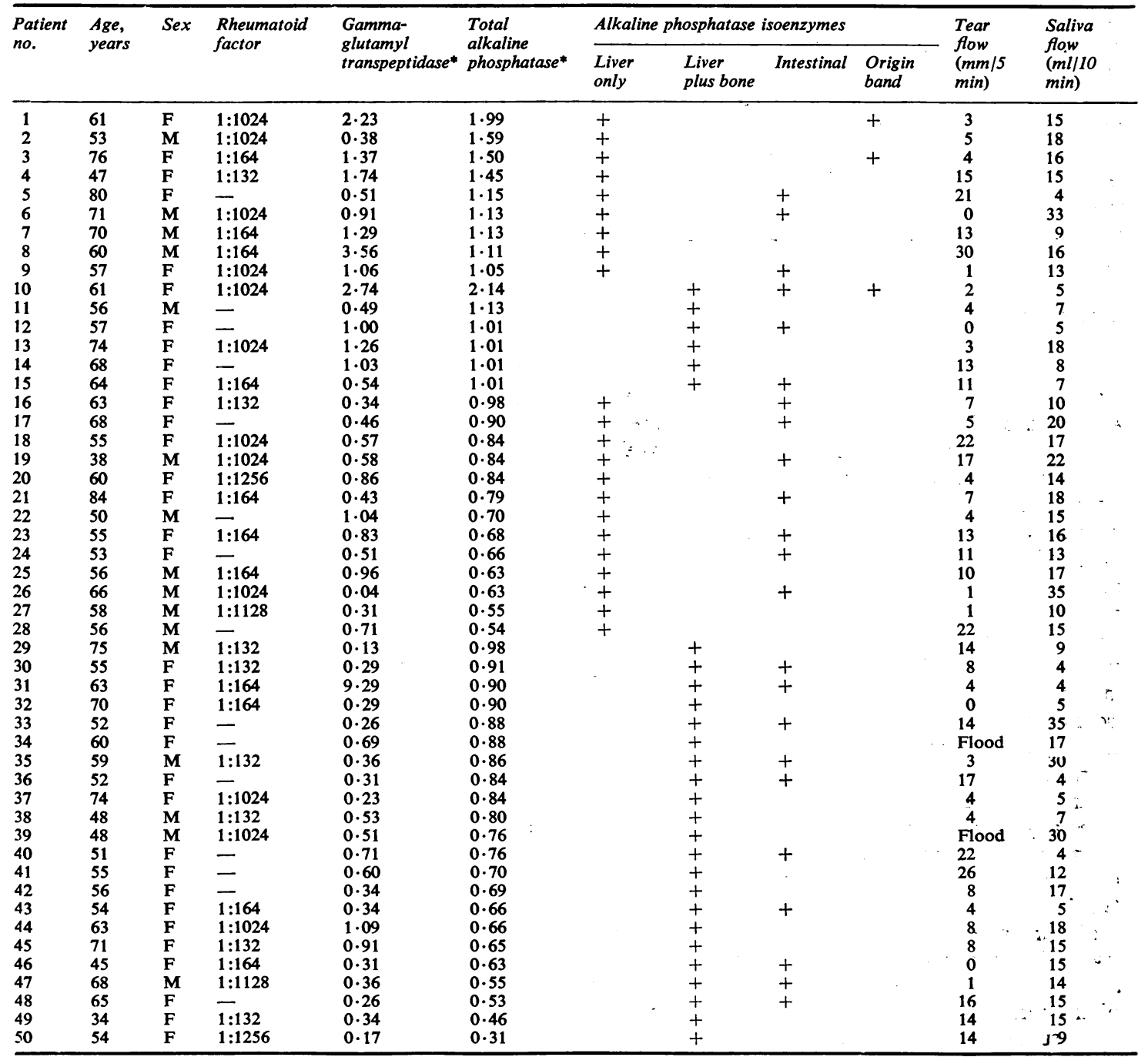

*Times upper limit of normal. $+=$ present. 
and bone isoenzymes but with the liver band markedly stronger in each case, suggesting that the elevations in total ALP were due to increases in the liver isoenzyme. Three of the 15 also had a band which remained at the site of application-the socalled 'origin band', which so far has been found only in patients with liver disease (Warnes et al., 1976). Of the 35 patients with normal ALP levels 13 had the liver isoenzyme as the sole component of the main band position. The remaining 22 all showed both liver and bone isoenzymes, but in $16(73 \%)$ the liver component was stronger. In $4(18 \%)$ the two isoenzymes were of approximately equal strength, while in 2 the bone component was stronger.

Intestinal ALP was found as frequently in patients with raised ALP (6 out of 15) as in those with normal enzyme levels (17 out of 35) - an incidence which is similar to that found in normal subjects (Warnes et al., 1977).

Nine of the 15 patients with raised liver ALP had concomitant elevations in serum GGT. By comparison only 3 of the 35 with normal ALP levels had an elevated GGT $(P<0.0005)$, and 1 of these (patient 31 , Table 2) was the only patient receiving barbiturates for night sedation at the time of study.

\section{Discussion}

In the present study biochemical evidence of liver disease (consisting mainly of elevations in serum ALP and/or GGT) was found in $45 \%$ of the 100 patients with rheumatoid arthritis. In skeletal disorders elevations in serum ALP are often considered to be due to increased levels of the bone isoenzyme. It is of interest, therefore, that only 2 $(4 \%)$ of the 50 patients whose sera were studied had the bone isoenzyme as the dominant electrophoretic band. Indeed the liver isoenzyme was the sole or major component even in those with normal total ALP levels. This is in contrast to our findings in normal subjects, in only $32 \%$ of whom the liver isoenzyme was predominant, and never as the sole component (Warnes, 1972; Warnes et al., 1976).

Increases in serum GGT levels are more particularly associated with disease of the liver and especially with disorders involving the biliary tract (Lum and Gambino, 1972). Enzyme-inducing agents, including barbiturates, can produce elevations in GGT (Rosalki et al., 1971), but this applied to only 1 of our patients, who did have a very high serum level of this enzyme-without a concomitant elevation in ALP. In the 9 patients (representing $18 \%$ of the series) who had both raised GGT and liver ALP subclinical liver disease would seem to be a real possibility.
Although most of the patients were receiving one or more potentially hepatotoxic therapeutic agents (aspirin, phenylbutazone, gold), we were unable to show alterations in liver function related to any $\stackrel{S}{\rightarrow}$ individual drug or to any of many drug combinations We were also unable to implicate excessive alcohol consumption or past or present infection with hepatitis B virus as a cause of the liver function $\stackrel{\varnothing}{\triangle}$ abnormalities. Smooth muscle antibody was found in in $7 \%$ of patients and antinuclear antibody in $19 \%$, but the incidence and titres recorded are within published values for normal persons of similar ages (Anderson, 1975). Moreover, with the exception of the 1 patient with antimitochondrial antibody, the presence of these immunological markers of chronic $c$ liver disease did not correlate with increased levels of the liver enzymes nor with lacrimal or salivary gland dysfunction.

The finding that most patients with xerostomia $\stackrel{\circ}{3}$ and/or xerophthalmia had significantly higher ALP levels than those without is in agreement with observations of other workers (Webb et al., 1975) and is of interest in the context of other known interrelationships between joint disease and liver $\underset{\mathbb{D}}{\mathbb{Z}}$ disease. A number of rheumatic disorders are $\vec{A}$ included in the spectrum of multisystem involve ment which is a characteristic feature of chronis. active hepatitis (CAH) and primary biliary cirrhos (PBC). Arthropathies occur in up to $27 \%$ of CAH and in $5-10 \%$ of PBC patients (Golding et al., 1973), and scleroderma has been reported in $17 \%$ of those with PBC (Clarke et al., 1978). Both rheumatoid arthritis (as Sjögren's syndrome) and scleroderma (Alarcon-Segovia et al., 1974) are frequently associated with the sicca syndrome, which also occurs in $75-100 \%$ of patients with PBC (Alarcon-Segovia et al., 1973; McFarlane et al., 1976). Some of these systemic manifestations might be related to the 응 presence of circulating immune complexes, which have been reported particularly in the sera of PBC patients (Wands et al., 1978). Immune complexes are also found in rheumatoid arthritis and could account for the portal tract mononuclear cell infiltration observed in liver biopsies from rheu- $\rightarrow$ matoid patients (Lefkovits and Farrow, 1955; Webb et al., 1975; Dietrichson et al., 1976). In our N patients, however, the biochemical evidence was more suggestive of bile duct damage, and it has been shown experimentally that injection of immune $\mathrm{W}$ complexes into the systemic circulation does not lead to bile duct damage (Paronetto et al., 1962).

A more likely hypothesis, for which we have $\mathbb{D}$ obtained some evidence, is that immunologically? mediated damage to structures in one organ (as 0 occurs in the livers of patients with CAH or PBC) leads to sensitisation to a number of self-antigens, $\stackrel{?}{?}$ 
some of which cross-react with antigens in other tissues in which similar immunologically mediated disease processes may consequently be initiated (Tsantoulas et al., 1974a; McFarlane et al., 1976). Approximately $80 \%$ of PBC patients show in-vitro leucocyte migration inhibition in response to biliary antigens (Eddleston et al., 1973; Tsantoulas et al., 1974b; McFarlane et al., in press). We have also shown that patients with sicca syndrome secondary to either rheumatoid arthritis or primary biliary cirrhosis show cellular immune responses to salivary antigens which cross-react immunologically with antigens present in the normal human biliary tract (McFarlane et al., 1976; Sullivan et al., 1978; Wojcicka, 1979). In the present study there appeared to be an association between the presence of the sicca syndrome and raised serum levels of liver enzymes, and it is possible that the development of hepatobiliary lesions in rheumatoid arthritis might be related to immune responses to crossreacting salivary and biliary antigens. Further studies will be required to determine whether cellular immune responses to biliary antigens (similar to those demonstrated in PBC) are to be found in patients with rheumatoid arthritis.

\section{References}

Alarcon-Segovia, D., Diaz-Jouanen, E., and Fishbein, E. (1973). Features of Sjögren's syndrome in primary biliary cirrhosis. Annals of Internal Medicine, 79, 31-35.

Alarcon-Segovia, D., Ibanez, G., Hernandez-Ortiz, J., Velazquez-Forero, F., and Gonzalez-Jiminez, Y. (1974). Sjogren's syndrome in progressive systemic sclerosis (scleroderma. American Journal of Medicine, 57, 78-85.

Andersen, P. (1975). Correlation of smooth muscle and nuclear antibodies in normal subjects. Clinical and Experimental Immunology, 27, 74-78.

Anderson, L. G., Tarpley, T. M., Talal, N., Cummings, N. A., Wolf, R. O., and Schall, G. L. (1973). Cellular versus humoral autoimmune responses to salivary gland in Sjogren's syndrome. Clinical and Experimental Immunology, 13, 335-342.

Bloch, K. J., Buchanan, W. W., Wohl, M. J., and Bunim, J. J. (1965). Sjogren's syndrome. A clinical, pathological and serological study of 62 cases. Medicine, 44, 187-231.

Clarke, A. K., Galbraith, R. M., Hamilton, E. B. D., and Williams, R. (1978). Rheumatic disorders in primary biliary cirrhosis. Annals of the Rheumatic Diseases, 37, 42-47.

Cockel, R., Kendall, M. J., Becker, J. F., and Hawkins, C. F. (1971). Serum biochemical values in rheumatoid disease. Annals of the Rheumatic Diseases, 30, 166-170.

Dietrichson, O., From, A., Christoffersen, P., and Juhl, E. (1976). Morphological changes in liver biopsies from patients with rheumatoid arthritis. Scandanavian Journal of Rheumatology, 5, 65-69.

Eddleston, A. L. W. F., McFarlane, I. G., Mitchell, C. G., Reed, W. D., and Williams, R. (1973). Cell-mediated immune responses in primary biliary cirrhosis to a protein fraction from human bile. British Medical Journal, 4, 340-342.

Golding, P. L., Bown, R., Mason, A. M. S., and Taylor, E.
(1970). 'Sicca complex' in liver disease. British Medical Journal, 4, 340-342.

Golding, P. L., Smith, M., and Williams, R. (1973). Multisystem involvement in chronic liver disease: studies on the incidence and pathogenesis. American Journal of Medicine, 55, 772-782.

Lef kovits, A. M., and Farrow, I. J. (1955). Liver in rheumatoid arthritis. Annals of the Rheumatic Diseases, 14, 162-168.

Lum, G., and Gambino, S. R. (1972). Serum gamma glutamyl transpeptidase activity as an indicator of disease of liver, pancreas or bone. Clinical Chemistry, 18, 358-362.

McFarlane, I. G., Wojcicka, B. M., Tsantoulas, D. C., Funk, C., Portmann, B., Eddleston, A. L. W. F., and Williams, R. (1976). Cellular immune responses to salivary glands in autoimmune liver disease with sicca syndrome. Clinical and Experimental Immunology, 25, 389-395.

McFarlane, I. G., Wojcicka, B. M., Tsantoulas, D. C., Portmann, B., Eddleston, A. L. W. F., and Williams, R. (In press). Leucocyte migration inhibition in response to biliary antigens in primary biliary cirrhosis, sclerosing cholangitis and other chronic liver diseases. Gastroenterology.

Paronetto, F., Woolf, N., Koffler, D., and Popper, H. (1962). Response of the liver to soluble antigen antibody complexes. Gastroenterology, 43, 539-546.

Reed, W. D., Mitchell, C. G., Eddleston, A. L. W. F., Lee, W. M., Williams, R., and Zuckerman, A. J. (1974). Exposure and immunity to hepatitis $B$ virus in a liver unit. Lancet, 2, 581-583.

Ropes, M. W., Bennett, G. A., Cobb, S., Jacox, R., and Jessar, R. A. (1958). Revision of diagnostic criteria for rheumatoid arthritis. Bulletin of the Rheumatic Diseases, 9 , 175-177.

Rosalki, S. B., Tarlow, D., and Rau, D. (1971). Plasma gamma-glutamyl transpeptidase elevation in patients receiving enzyme-inducing drugs. Lancet, 2, 376-377.

Soborg, M., and Bertram, U. (1968). Cellular hypersensitivity in Sjögren's syndrome. Acta Medica Scandinavica, 184, 319-322.

Sullivan, S., Fernandes, L., McFarlane, I. G., Wojcicka, B., Eddleston, A. L. W. F., Doniach, D., Hamilton, E., and Williams, R. (1978). Impairment of lachrymal and salivary secretion and cellular immune responses to salivary antigens in rheumatoid arthritis. Annals of the Rheumatic Diseases, 37, 164-167.

Tiger, L. H., Gordon, M. H., Ehrlich, G. E., and Shapiro, B. (1976). Liver enlargement demonstrated by scintigraphy in rheumatoid arthritis. Journal of Rheumatology, 3, 15-20.

Tsantoulas, D. C., McFarlane, I. G., Eddleston, A. L. W. F., and Williams, R. (1974a). Cell-mediated immunity to human Tamm-Horsfall glycoprotein in autoimmune liver disease with renal tubular acidosis. British Medical Journal, 4, 491-494.

Tsantoulas, D. C., McFarlane, I. G., Portmann, B., Eddleston, A. L. W. F., and Williams, R. (1974b). Sensitisation to human bile proteins in primary biliary cirrhosis and active chronic hepatitis: Demonstration of antigenic material in bile duct epithelial cells. Digestion, 10, 305 (abstract).

Wands, J. R., Dienstag, J. L., Bhan, A. K., Feller, E. R., and Isselbacher, K. J. (1978). Circulating immune complexes and complement activation in primary biliary cirrhosis. New England Journal of Medicine, 298, 233-237.

Warnes, T. W. (1972). Alkaline phosphatase. Gut, 13, 926-937.

Warnes, T. W., Hine, P., and Kay, G. (1976). Polyacrylamide disc gel electrophoresis of alkaline phosphatase isoenzymes in bone and liver disease. Journal of Clinical Pathology, 29, 782-787. 
506 Fernandes, Sullivan, McFarlane, Wojcicka, Warnes, Eddleston, Hamilton, Williams

Warnes, T. W., Hine, P., and Kay, G. (1977). Intestinal alkaline phosphatase in the diagnosis of liver disease. Gut, 18, 274-278.

Webb, J., Whaley, K., MacSween, R. N. M., Nuki, G., Dick, W. C., and Buchanan, W. W. (1975). Liver disease in rheumatoid arthritis and Sjögren's syndrome. Prospec- tive study using biochemical and serological of hepatic dysfunction. Annals of the Rheumatic Diseases, 34, 70-81. Wojcicka, B. M. (1979). Separation and characterisation of bile antigens. In Immune Reactions in Liver Disease. Edited by A. L. W. F. Eddleston and R. Williams. Pitman Medical: London. 